Article

\title{
Capability Framework for Sustainable Manufacturing of Sports Apparel and Footwear
}

Aleksandar Subic ${ }^{1, *}$, Bahman Shabani ${ }^{2}$, Mehdi Hedayati ${ }^{3}$ and Enda Crossin ${ }^{3}$

1 School of Aerospace, Mechanical and Manufacturing Engineering, RMIT University, P.O. Box 71 Bundoora VIC 3083, Victoria 3083, Australia

2 School of Aerospace, Mechanical and Manufacturing Engineering, RMIT University, GPO Box 2476, Melbourne, Victoria 3001, Australia; E-Mail: bahman.shabani@rmit.edu.au

3 Centre for Design, School of Architecture and Design, RMIT University; GPO Box 2476, Melbourne, Victoria 3001, Australia; E-Mails: mehdi.hedayati@rmit.edu.au (M.H.); enda.crossin@rmit.edu.au (E.C.)

* Author to whom correspondence should be addressed; E-Mail: aleksandar.subic@rmit.edu.au; Tel.: +61-3-9925-6000; Fax: +61-3-9925-6108.

Received: 16 July 2012; in revised form: 24 August 2012 / Accepted: 27 August 2012 / Published: 5 September 2012

\begin{abstract}
The sporting goods sector is characterized by large volumes of production, high levels of consumption and short product life cycles resulting in high disposal rates and waste. Manufacturing of sports products is distributed globally through tier-based supply chains and complex logistics systems. Companies within such supply chains have different levels of capability in sustainable manufacturing, which impacts on the sustainability of the overall business. Reducing environmental impacts is of particular concern for companies at present, due to heightened requirements for the reduction of energy and water consumption, waste and greenhouse gas (GHG) emissions. This article describes outcomes of a research project conducted in collaboration with a global sporting goods manufacturer that focused on the development of relevant capabilities across their supply chain for sustainable manufacturing of sports apparel and footwear. The article presents the developed sustainable manufacturing framework and capability assessment results obtained for selected companies within the supply chain of this global manufacturer in Asia.
\end{abstract}

Keywords: sustainable manufacturing framework; capability assessment; sports products 


\section{Introduction}

The sporting goods industry is characterized by mass volume production and distributed manufacturing across different geographical regions, which involves high levels of resources consumption, waste and other environmental emissions. The manufacturers of sporting goods are confronted with the need to address corporate sustainability responsibility model as the prevailing model across their entire supply chain. To address these ongoing demands, the practices and associated knowledge, skills and attitudes of the workforce across the entire supply chain must meet an appropriate standard in a consistent manner based on best practice in order to achieve this objective.

Contractors of major sporting goods manufacturers may consume as much as $80 \%$ of the resources used by the supply chain through consumption of raw materials, energy and water. The sports apparel and footwear industries rely on tiered supply chains associated with large multinational companies, located worldwide and in particular in developing countries (primarily in Asia). As such, the environmental impact (and sustainability in general) of these industries depends, to a great extent, on how these industries can effectively influence the suppliers to adopt more sustainable technologies and practices. Achieving a sustainable framework across the entire business requires a strategic approach that captures the multiple dimensions of sustainability (i.e., economic, social and environmental) and relates these to the specific targets and timelines for achieving them. The focus of this study was on the environmental aspects of sustainability.

Reducing waste and hence the cost and environmental impact associated with the waste is of strategic importance in sustainable manufacturing of sporting goods. The regular accurate measurement of key performance data enables companies to monitor their environmental performance over time, identify relevant trends, set benchmarks and identify potential savings. Reducing energy and water consumption, reducing and/or eliminating volatile organic compounds in sports products are some of the environmental objectives currently being made in the sports apparel and footwear industries. There are various pilot projects undertaken within the global sporting goods industry and other sectors aimed at developing sustainable technologies and practices. However, there is a limited evidence to suggest that these initiatives have been widely adopted and applied. This issue is likely due to lack of consistency of standard practices and capabilities across the entire supply chain. Although strategies and leadership are emerging in this domain, there are still many challenges to be overcome if sustainability is to become a realistic platform for new business models.

Some sustainability initiatives and practices are not being implemented consistently across the supply chain. Corporations must work more closely with their suppliers to make their value chains sustainable. Sustainability criteria must be integrated into product design and manufacturing using lifecycle assessment criteria, lifecycle costing and product/process sustainability targets. Implementation of sustainable practices and associated targets will lead to sustainability improvements in areas such as product design and manufacturing, policy making, workforce and resource management, and marketing. The materials and processes used in the manufacturing processes are of key concern as they carry with them many potential environmental risks. For example, while many corporations state that they aim to increase the percentages of organic cotton and other natural materials in their products, synthetic materials such as polyesters are being adopted as the main raw materials for sports apparel instead. Synthetic fibres are derived from polymers produced primarily 
from petrochemicals through energy-intensive processes. Also, the environmental impact of using composites in mass produced products is emerging as a critical issue for sporting goods industry. The demand for textile fibre worldwide is increasing along with the demand for high performance sports apparel. Performance apparel items impact on the environment at every stage of their life cycle. Performance apparel and sports shoes in general have a heavy carbon footprint, which results primarily from pollution, consumption of non-renewable resources and waste.

Sustainability frameworks are typically focused on strategy and decision making processes, rather than capability assessment. A number of sustainability capability frameworks have been proposed to date. de Bakker and Neijhof developed a framework for social aspects of sustainability [1], however specific capabilities were not proposed. Kinderyte reviewed a number of sustainability assessment frameworks [2]. One of these frameworks, the Sustainability Assessment for Enterprises (SAFE), developed by the Wuppertal Institute, is designed to assess a company's performance on economic, ecological, social and communication metrics. One aspect of the SAFE framework is the identification of the qualification needs of employees [2]. The SAFE system, however, does not extend down the supply chain. Likewise, the Sustainability Competency and Opportunity Rating and Evaluation (SCORE) system [3] includes aspects of assessing capability across sustainability practices, but does not extend this assessment to the supply chain. A common aspect of these frameworks is the need and importance of involving stakeholders in framework development [1,4], including the company, its customers and suppliers, and government agencies. After reviewing existing frameworks, it was identified that there was a need to develop a new framework to assess particular capabilities across the supply chain. This paper focuses on the development of a new capability framework, and how it was applied to an existing supply chain within the sports apparel and footwear industries.

The research presented in this article is aimed at developing a sustainable manufacturing framework by identifying the capabilities that tier 1 and tier 2 suppliers require in order to be able to achieve the desired environmental targets. In the framework presented, these environmental targets include the reduction of energy and water usage, and the reduction of waste and emissions generation. Tier one companies supply products directly to the original equipment manufacturer (OEM), while tier two companies supply products to tier one companies. The research is primarily concerned with formulating critical sustainable manufacturing competencies, identifying capacity gaps and training needs, mapping existing opportunities and developing a strategic capability development plan. Furthermore, this research aims to help drive closer collaboration for improved performance across the supply chain of a global sporting goods manufacturer (mentioned as 'the manufacturer' in this paper) and the broader industry while initially focusing on their operations in Asia. This manufacturer selected five of its Asian tier 1 and 2 suppliers for participation in this study; however, it is argued that the developed framework can be applied to other industries and supply chains.

\section{Sustainable Manufacturing Framework (SMF)}

In order to assess capabilities across a supply chain in a comprehensive and systematic manner, a capability Assessment Tool (CAT) was needed to ensure consistent application. To develop this tool an assessment framework or Sustainable Manufacturing Framework (SMF) was required. To establish this framework, a situation analysis was first conducted by visiting the five participating suppliers. 
This analysis was aimed at understanding the context under which the tier 1 and 2 apparel and footwear suppliers of the global sporting goods manufacturer, focused by this study, operate in Asia and to identify opportunities for knowledge and skill development. This situation analysis considered a number of parameters, including local infrastructure, resource efficiency practices, industry health and safety, management practices, workforce training, and technology level. Moreover, selected personnel of this manufacturer, in Asia and globally, were consulted to identify existing sustainability initiatives. The identified projects were then reviewed and analyzed by considering their objectives, processes and outcomes, challenges, lessons learnt, and the suppliers' feedback. A comprehensive review of relevant industry reports [5-20] and training resources [21-44] has been undertaken to ensure that the research project is aligned with the industry partner's strategic plan, sustainability objectives and targets (e.g. [6-8,13]).

The initial SMF consisted of three levels of capabilities (overall structure outlined in Figure 1): the first level reflected the key environmental indicators and initiatives set by the manufacturer [45] and included energy and greenhouse gas emissions, water, materials, wastewater, solid waste, air emissions, noise, chemicals, soil and ground water, management initiatives and emission mapping; the second level was related to industry practices within the environmental indicators and initiatives; and finally, the third level was related to practical implementation of environmental initiatives. The first and second level capabilities were developed by analyzing and interpreting environmental initiatives, standards, and, where possible, existing practices across the supply chain of the manufacturer. The corporate documents of this manufacturer were used to develop the first and second levels. The third level capabilities were largely based on existing competency standards from the Australian Quality Training Framework [46]. This initial revision of framework included 11 capabilities in the first level, followed by 45 and 347 capabilities in the second and third levels, respectively. This initial SMF was subject to critical review by the manufacturer and its suppliers.

Figure 1. The overall structure of sustainable manufacturing framework (SMF).

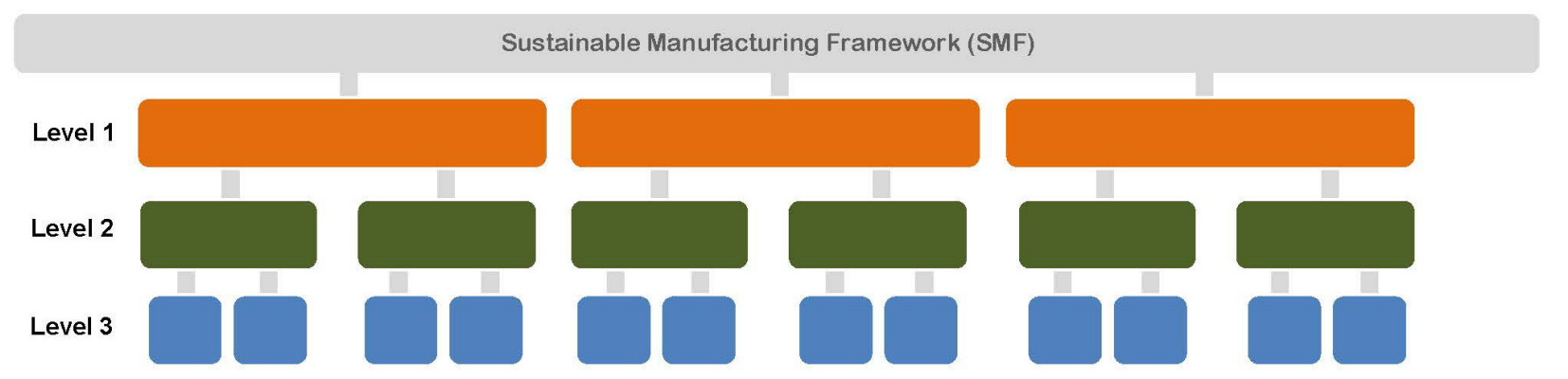

Following this critical review, the final SMF, Figure 2, was developed by incorporating feedback from the manufacturer's stakeholders and the participating suppliers. The final SMF maintains the three-level structure, with fewer and simplified levels 2 and 3 capabilities. The finalized SMF included eight level one capabilities, termed "clusters" and eighteen level two capabilities, termed "applied outcomes". As shown in Figure 2, these clusters were broadly grouped into three areas of sustainable manufacturing: resource efficiency (cluster 1 to 3), emissions reduction (clusters 4 and 5), and improved management practices (clusters 6 to 8). These groups and clusters were aligned with the main sustainability objectives of the manufacturer. 
Figure 2. Levels 1 and 2 of the finalized sustainable manufacturing framework.

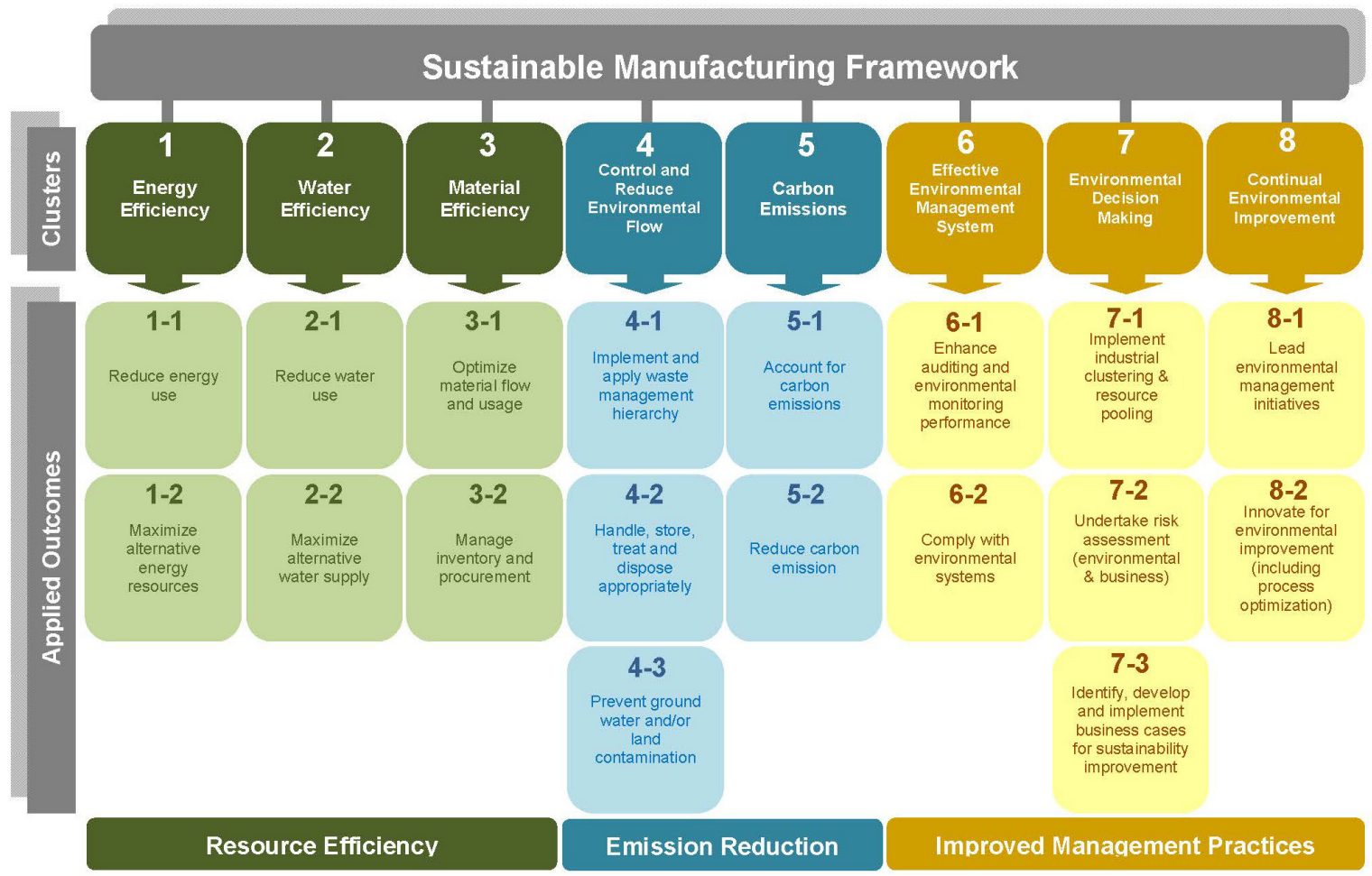

The finalized SMF (Figure 2) was used to develop a Capability Assessment Tool (CAT). This development incorporated assessment methods, indicators of attainment and an outline of the core capabilities (the capabilities, without which, no other capabilities would be possible) expected for the participating suppliers.

\section{Capability Assessment Tool (CAT)}

Four assessment methods were developed and employed to assess the level three capabilities. Each core capability was assessed using at least two of these four methods, while the remaining capabilities were assessed using at least one method. This approach was undertaken to increase the reliability and robustness of the assessment. The four methods used in this assessment were:

1- walk-through assessment based on observing work practices,

2- response to written questions based on simulated workplace activities,

3 - interview responses to pre-determined questions, and

4- work samples (e.g., a project report) indicating prior demonstration of capability.

To ensure a fair, robust, and reliable assessment, the capabilities were assessed by two independent teams (with up to four personnel in each together): one team from RMIT University and one team from the manufacturer. The capabilities were assessed on a sliding scale, ranging from one to five (unsatisfactory to excellent) as shown in Table 1.

To obtain the final assessment results for the level three capabilities, an average rating was calculated based on the different assessment methods and assessment teams. The level one and two capabilities were based on a non-weighted average of the underpinning level two and level three 
capabilities, respectively. Where a level three or level two capability was not relevant to a particular industry or company, it was removed from the assessment calculation.

Table 1. The sliding scale used for assessing capabilities.

\begin{tabular}{ccl}
\hline Rating & Descriptor & Example of Attainment \\
\hline $\mathbf{1}$ & Unsatisfactory & Fail—Lack of any capability \\
$\mathbf{2}$ & Satisfactory & Pass—Just enough, minimal or marginal \\
$\mathbf{3}$ & Good & Developing capability above minimal or marginal can do basic things independently \\
$\mathbf{4}$ & Very Good & Proficient—Developed capability, can plan regular actions independently \\
$\mathbf{5}$ & Excellent & Mastery, excellent - Can lead changes, plan improvements, and grasp new techniques \\
\hline
\end{tabular}

\section{Capability Assessment and Gap Analysis}

\subsection{Capability Assessment and Gap Analysis Results}

The capability gaps were calculated from the difference between the level two capability score and the minimum expectation levels. These minimum expectations, for the eighteen applied outcomes, under the eight clusters of CAT, were determined by the manufacturer internally, by considering the tier level and industry type; they also considered the requirement within their supply chain in order to achieve their strategic environmental targets, e.g. [6-8], as well as taking into account the environmental impacts and risks of these different types of industries. These minimum expectations were then used as references to identify capability gaps within the sample group of tier 1 and 2 apparel and footwear suppliers participated in this study, Table 2.

Table 2. Apparel and footwear tier 1 and 2 suppliers participated in the study.

\begin{tabular}{cll}
\hline Supplier Name & Industry Type & Short Description \\
\hline A & Footwear, Tier 1 & $\begin{array}{l}\text { Making sport shoes. The major manufacturing operations include cutting, } \\
\text { stitching, gluing, finishing, and packaging. }\end{array}$ \\
\hline B & Footwear, Tier 1 & $\begin{array}{l}\text { Making sport shoes for major global sporting manufacturers. The main } \\
\text { manufacturing operations include cutting, stitching, gluing, finishing, } \\
\text { and packaging. }\end{array}$ \\
\hline C & Footwear, Tier 2 & $\begin{array}{l}\text { Making high-technology plastic shoe components. The major } \\
\text { manufacturing processes include design, blending of raw materials, } \\
\text { injection molding, and packaging. }\end{array}$ \\
\hline D & Apparel, Tier 1 & $\begin{array}{l}\text { Making sport clothing products with five major divisions including: } \\
\text { fabric warehouse; cutting/patterns; sewing; finishing; and sampling. }\end{array}$ \\
\hline E & Apparel, Tier 2 & $\begin{array}{l}\text { Making textile products. The major manufacturing processes include } \\
\text { desizing, scouring, washing, mercerizing, bleaching, printing and finishing. }\end{array}$ \\
\hline
\end{tabular}

The identified capability gaps are reviewed in this section and will be further analyzed and discussed in details in Section 4.2 of this paper.

The assessment results and associated gaps for Supplier A are shown in Figure 3. Supplier A's capabilities in energy and water efficiency were both assessed to be unsatisfactory to satisfactory. No capabilities were found within this supplier in identifying the most energy and water intensive processes through performing energy/water hotspot analysis throughout their factory. They also had lack of capability in implementing, operating, and maintaining alternative energy systems and water 
resources. Their capability was close to that expected by the manufacturer in material efficiency (2.6) while they needed to improve their capability to identify the variables causing waste generation as this assists in recognizing opportunities to improve practices/procedures for material use. Below satisfactory performance of Supplier A in applying waste management hierarchy and prevention of groundwater/land contamination led to an overall score of 1.8 in the control and reduce environmental flow cluster. They had some basic capabilities (at above satisfactory level) relating to identifying different types of greenhouse gas (GHG) emissions; however, their capabilities in investigating the processes generating GHG emissions and documenting the results of these investigations were unsatisfactory (GHG emission hotspot analysis). Despite some capabilities in identifying options to reduce GHG emissions, their capability in recommending and implementing these options were unsatisfactory. Under the 'environmental decision making' cluster, capabilities relating to risk assessment were close to good (2.7) and were driven by varied results across this applied outcome. This result was offset by lower capabilities in business case development (2.0) and industrial clustering/resource sharing (1.3). The research team found that Supplier A had unsatisfactory capability in considering social and environmental aspects in their business cases, which makes them unable to develop business proposals for sustainability improvements.

Figure 3. Supplier 'A' assessment results.

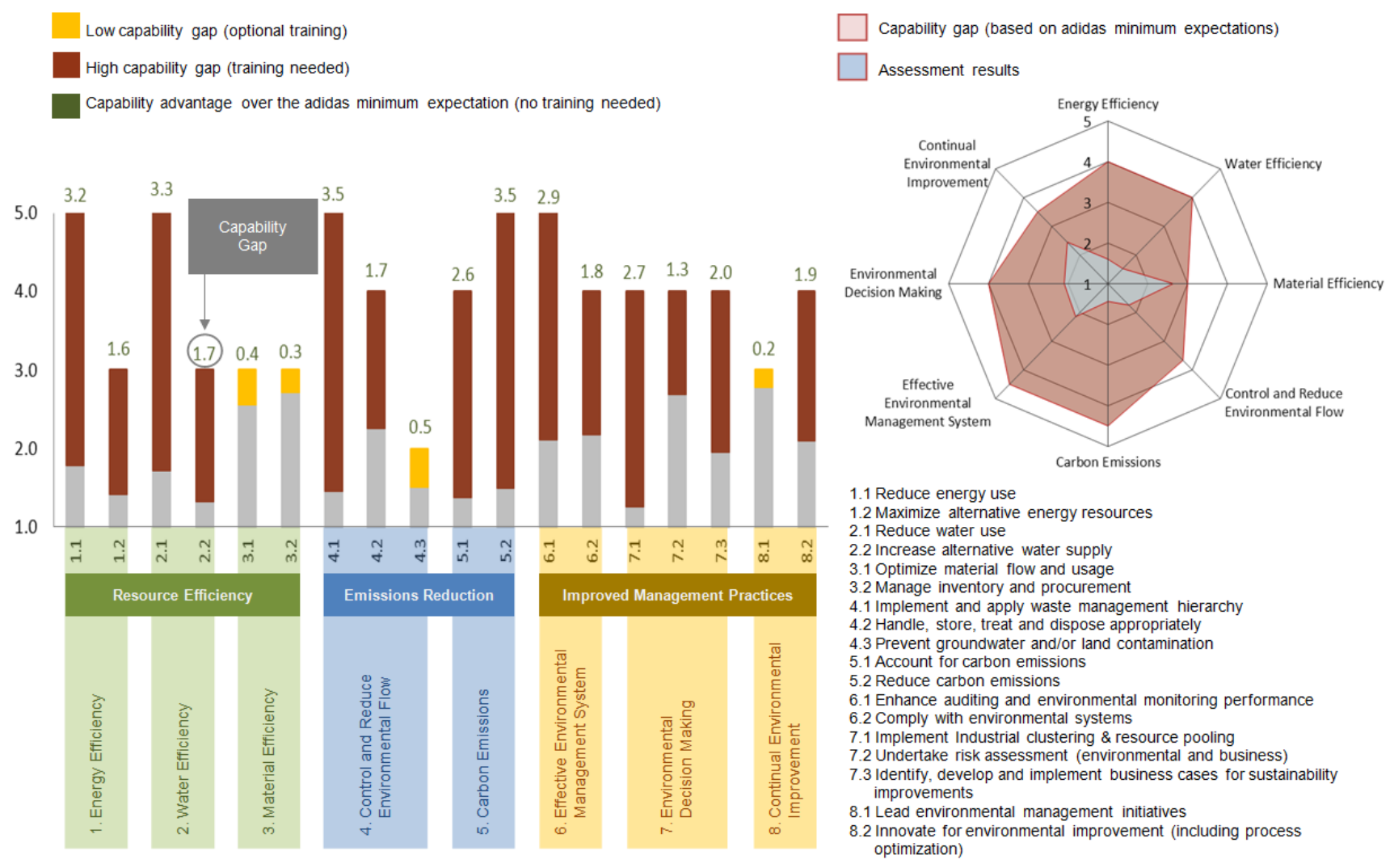

Supplier B assessment results (Figure 4) this supplier was good (3.0) in reducing their energy use but had almost unsatisfactory performance in employing alternative energy resources. Contrary to the energy efficiency cluster, Supplier B's capability in using alternative water resources were above good (3.4) and exceeded the manufacturer's expectation; however, their good capability (3.0) in 
reducing water use did not still meet the minimum expectation in this applied outcome (5.0). Supplier B's performance in material efficiency was assessed to be above the minimum expectation (3.0) by 0.5 and 0.3 scores difference the applied outcomes 3.1 and 3.2 respectively (see figure 2 for details of these applied outcomes). Above satisfactory capability in waste management hierarchy (2.3) was well below the excellent level (5.0) expected by the manufacturer, while their capabilities in waste handling, treatment and disposal and prevention of ground water and land contamination were either close to or above those minimums expected. Supplier B did not meet the minimum expectations in other clusters. Due to the nature of their operations and location, Supplier B was not assessed against the industrial clustering and resource pooling applied outcomes.

Figure 4. Supplier 'B' assessment results.

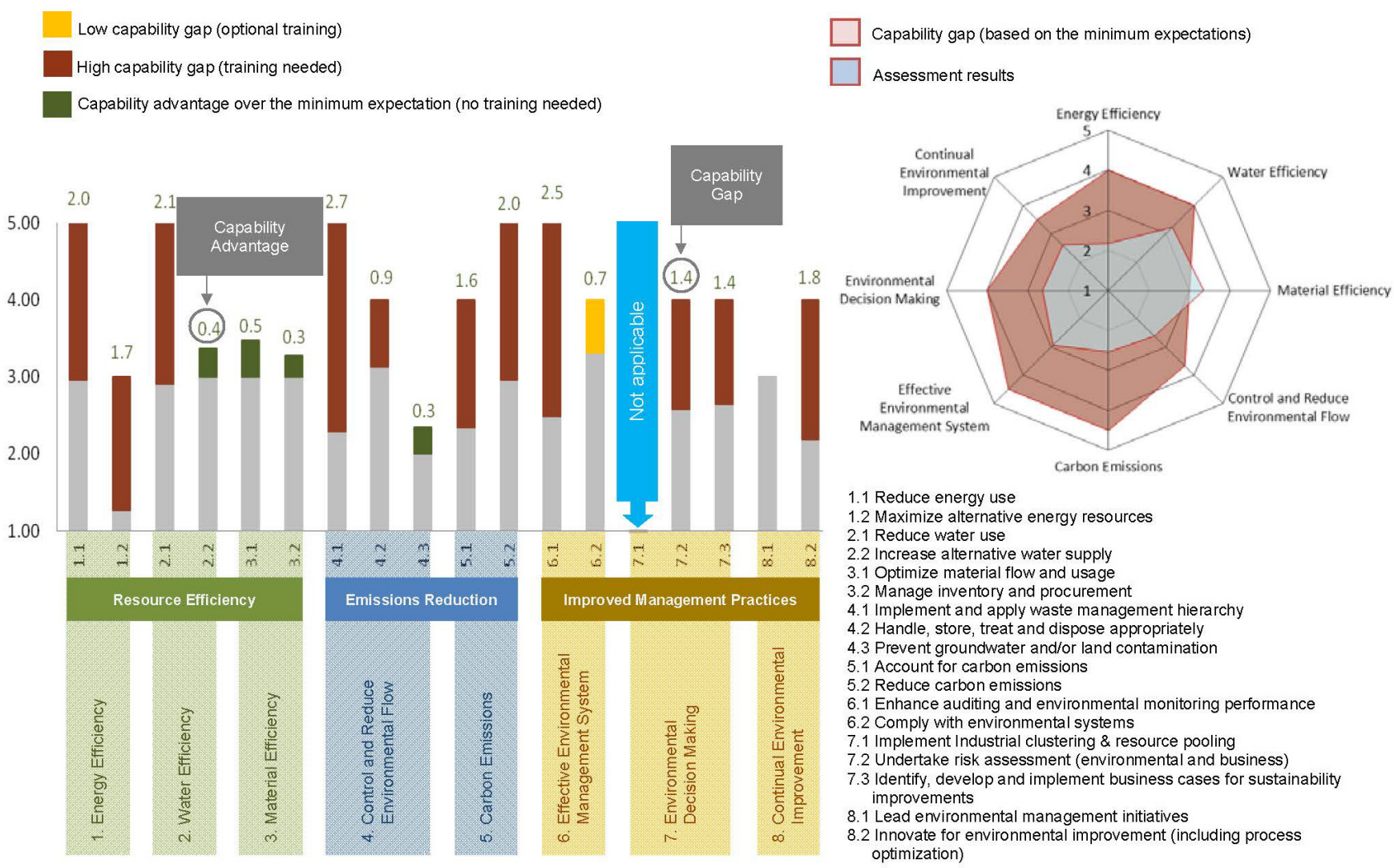

Supplier C results are shown in Figure 5. Their overall capability in 'energy efficiency' cluster was assessed to be just above satisfactory level (2.2). This supplier had good capability in measuring, recording and reporting of energy use; however, their capabilities in using these energy records to highlight energy reduction opportunities were limited. No capability in the operation and maintenance of alternative energy systems was observed for this supplier. Under the 'water efficiency' cluster, that was assessed to be satisfactory, Supplier $\mathrm{C}$ had a good capability in determining alternative water resources, along with a good understanding of associated water quality issues. However, this good capability was offset by lower capabilities in the operation and maintenance of alternative water systems. Like the energy efficiency cluster, Supplier C had a satisfactory capability in measuring, recording and reporting water use, but a lower capability in relating this use to prior consumption, and identifying improvement opportunities. The satisfactory outcome of the 'water efficiency' cluster 
could be reflective of the nature of the Supplier C's operations. That is, the majority of process water use (approximately 95\%) was attributed to the evaporation of cooling water for injection molding machines. This supplier showed good capabilities in applying continuous improvement to both energy and water efficiencies.

Figure 5. Supplier ' $C$ ' assessment results.

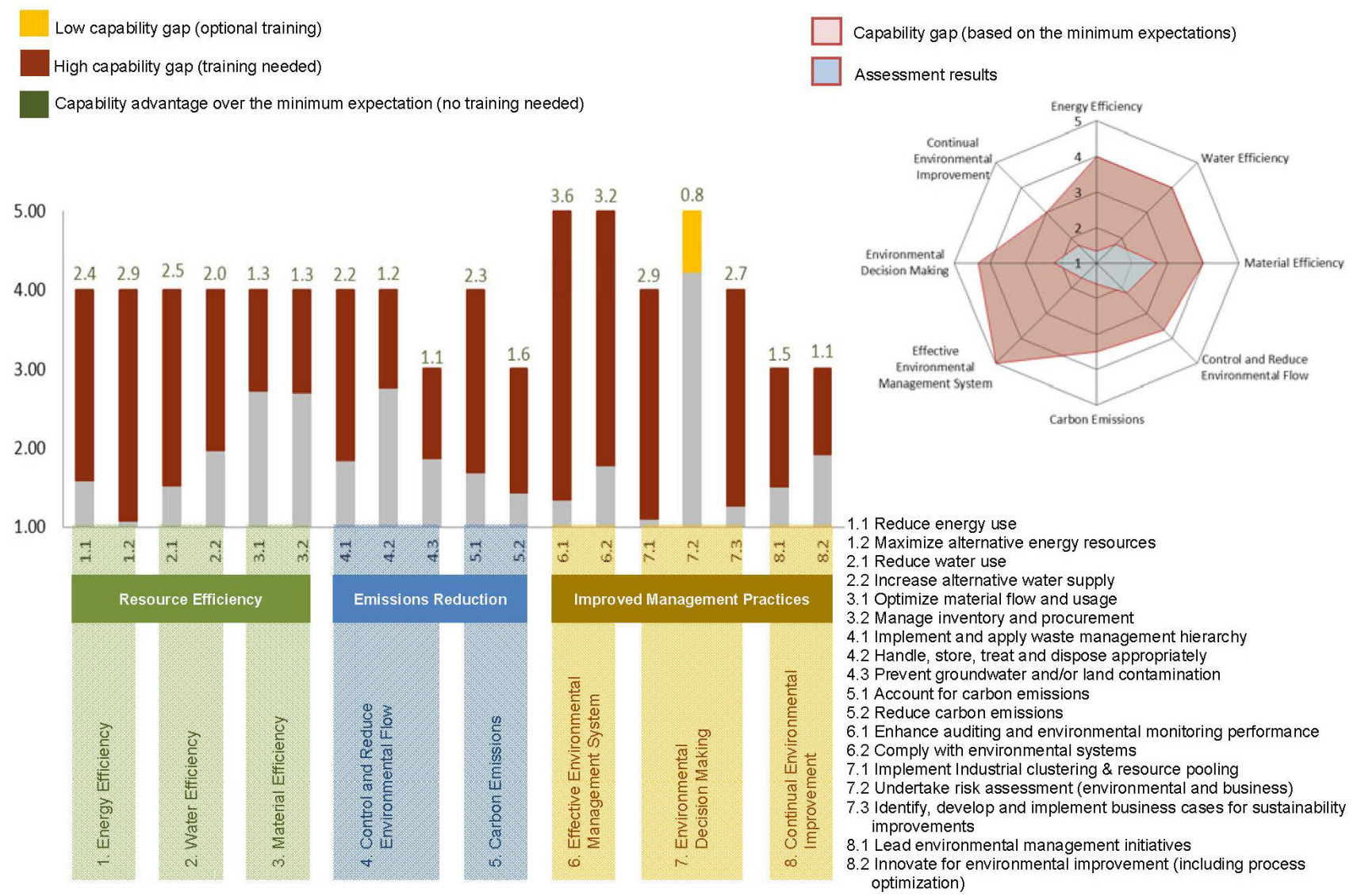

Supplier C' capabilities under 'optimize material flow and usage' applied outcome were assessed as being good to very good. They also showed a very good capability (3.9) in applying continuous improvement in material efficiency. Capabilities under 'manage inventory and procurement' were also assessed to be mainly about 'good', except unsatisfactory to satisfactory results in reporting of critical stock items (1.5), the development of vendor guidelines (1.3) and the sourcing of suppliers based on vendor guidelines (2.0). Supplier C adopted vendor guidelines based on the manufacturer's requirements and had not developed guidelines extending beyond these requirements. Due to the nature of their operations, supplier $\mathrm{C}$ was not assessed against the 'prevent groundwater and/or land contamination' applied outcome. As for 'carbon emissions' cluster, this supplier showed a broad range of capabilities, ranging from unsatisfactory to excellent. They demonstrated excellent capabilities relating to the identification of GHG emissions and their sources, and a good capability in calculating GHG emissions. However, under the same applied outcome, their capabilities relating to reporting of GHG emissions of the factory and comparing it with previous records were assessed as being unsatisfactory. As for the 'reduce carbon emissions' applied outcome (assessed to be below satisfactory), although Supplier C showed a satisfactory to good capability in determining options to 
reduce carbon emissions, their capability to rank operations based on their GHG emission production (GHG emission hotspot analysis) and recommending/implementing changes accordingly in order to reduce GHG emissions were assessed as being unsatisfactory to satisfactory.

Under the 'improved management practices' category of clusters, Supplier C had below satisfactory capability scores relating to internal auditing and above satisfactory capability score relating to compliance and targets. However, it is anticipated that their capability in establishing effective environmental management system would improve as they recently established such systems and undertook an ISO 14001:2004 audit. Supplier C was assessed as having a very good capability (3.8) in applying risk assessments in environmental and business decision making which was very close to that set by the manufacturer as minimum expectation for footwear tier 2 industries; however, their satisfactory capabilities in developing business cases for sustainability improvements and implementing shared resources were well below that expected as minimum (3.0). Despite having less than satisfactory performance in environmental reporting (1.3) the overall performance of supplier $\mathrm{C}$ in capabilities relating to leading environmental management initiatives were mainly assessed to be about good and close to minimum capability levels expected. Supplier $\mathrm{C}$ had a Kaizen system for process improvement in place, resulting in good capability scores for the promotion and implementation of process optimization strategies.

Figure 6. Supplier 'D' assessment results.

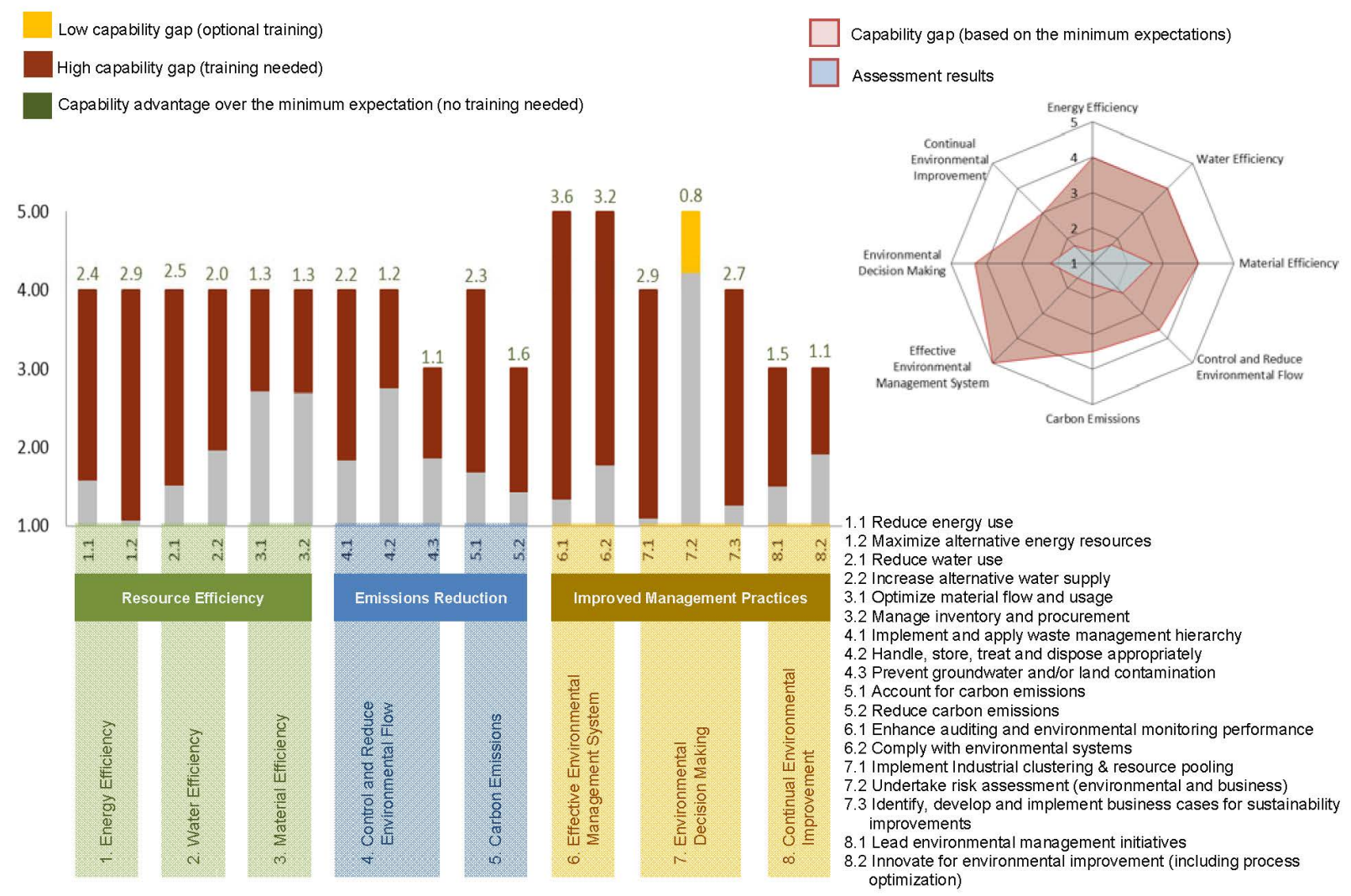

Supplier D was from apparel tier 1 industry and their results are shown in Figure 6. Under the resource efficiency category, Supplier D had below satisfactory capabilities in energy and water efficiency and close to good capability level in material efficiency. None of the clusters under resource 
efficiency category met the minimum expectations. In particular Supplier D had no capability (unsatisfactory) in using alternative energy resources.

Supplier D's capabilities relating to waste handling, treatment and disposal was assessed as being close to good (2.8) while their performance in continually improving these capabilities were assessed as unsatisfactory. This supplier had also relatively lower capabilities (just below satisfactory) relating to the waste management hierarchy and groundwater/land contamination (both 1.9). They were also assessed as being unsatisfactory in recording and reporting their GHG emissions at both factory and operation levels that led to a poor performance in introducing changes to reduce these emissions.

As for improved management practices, Supplier D was assessed as having mainly below satisfactory to unsatisfactory capabilities, except in those relating to risk assessment.

Figure 7. Supplier 'E' assessment results.

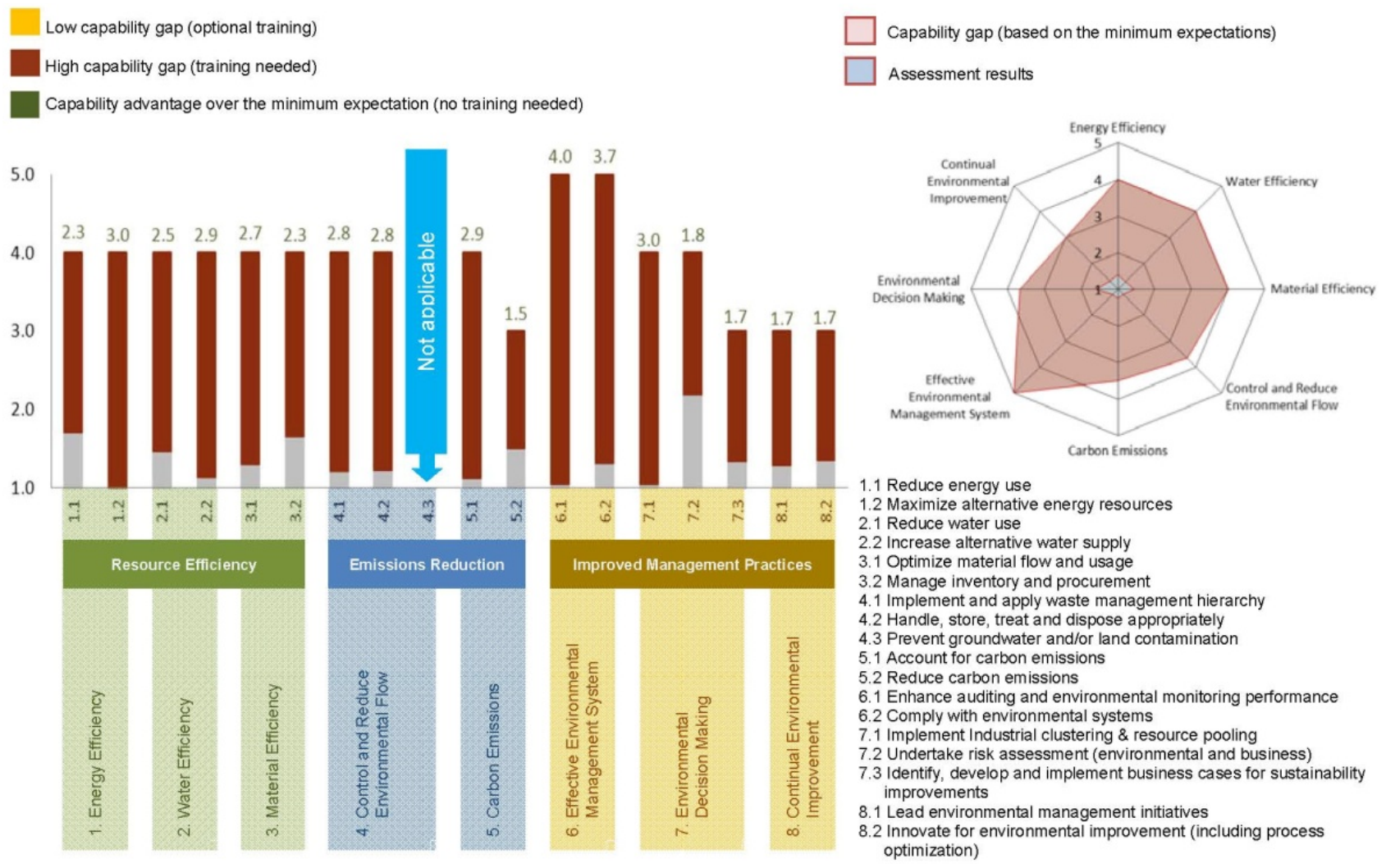

Supplier E was from apparel tier 2 industry. The assessment results for this supplier, Figure 7, showed the largest capability gaps in compare to the other participated suppliers. Poor capabilities in performing energy, water and material hotspot analysis (identifying the most resource-intensive processes), and unsatisfactory capability in using alternative water and energy resources were some of the key contributors in their poor performance in capabilities relating to resource efficiency. Due to the nature of their operations, supplier E was not assessed against the capabilities relating to the 'prevent groundwater and/or land contamination' applied outcome. Under the 'environmental decision making cluster' Supplier E showed just above satisfactory capability in risk assessment; however, all other capabilities under these clusters were assessed to be almost unsatisfactory. As for 'continual environmental improvement' this supplier demonstrated limited (less than satisfactory) capability in promoting process optimization strategies. However, their capabilities in establishing and reviewing 
environmental targets, strategies and timelines, as well as identifying the personnel capability gaps for achieving these targets were all unsatisfactory. They showed satisfactory capability $(\sim 2.0)$ in providing improvement ideas for work processes and implement changes accordingly and demonstrated no capability in measuring the environmental benefits/impacts of process changes, documenting the outcomes, communicating outcomes/achievements to stakeholders, and actively involving personnel in change implementation.

\subsection{Discussion of Capability Assessment and Gap Analysis Results}

The assessment results for the five suppliers participated in the study were reviewed in order to analyze the capability gaps and find the key reasons behind these gaps.

Supplier A was assessed as having considerable capability gaps in six out of eight clusters. This supplier was unable to implement and apply waste management hierarchy. Moreover, lack of capability in performing energy, water, and emission (i.e., carbon and waste) hotspot analysis was the common critical gap observed by the assessment teams for this supplier. Such capability gap led to poor results (relative to the minimum expectations set by the manufacturer) in 'energy efficiency', 'water efficiency', and 'carbon emissions' clusters. Supplier A had also smaller but still considerable capability gap in auditing and environmental monitoring performance. Gaps in material efficiency-related capabilities, as well as capabilities relating to prevention ground water and/or land contamination, and environmental management initiatives were existed but insignificant for this supplier.

The overall capability scores of Supplier B were relatively better than the other suppliers. However, still considerable capability gaps were identified in 11 out of 18 applied outcomes assessed for this supplier. Energy efficiency, and carbon emissions clusters had the biggest capability gaps followed by effective environmental management system, environmental decision making, control and reduce environmental flow, and continual environmental improvement. Furthermore, the following applied outcomes showed the highest capability gaps (in order) of approximately 2 or more:

- Implement and apply waste management hierarchy

- Enhance auditing and environmental monitoring performance

- Reduce water and energy use and carbon emissions

- Innovate for environmental improvement

Supplier C was assessed as not being able to perform resource/emissions hotspot analysis. This led to high capability gaps in 'energy efficiency', 'water efficiency', 'material efficiency', and 'carbon emissions' clusters. Some capabilities relating to determining the reasons for waste generation and developing actions/alternatives to reduce waste (both under waste management hierarchy applied outcome) were assessed as being below satisfactory that contributed to their overall poor performance in controlling and reducing their environmental flows. Capabilities relating to auditing and environmental monitoring (similar to suppliers A and B), industrial clustering and resource pooling, and business cases for sustainability improvement were other applied outcomes with considerable capability gaps.

Supplier D was also assessed as having lack of capability in performing resource/emissions hotspot analysis. Similar to other suppliers, such a capability gap contributed to a great extent to their poor 
performance in energy and water efficiencies, and carbon emissions clusters. 'Effective environmental management system' and 'environmental decision making' (excluding risk-assessment-related capabilities) are the clusters with highest capability gaps for this supplier. A small but negligible capability gap was also detected for material efficiency cluster.

The assessment results for supplier E showed substantial capability gaps in all clusters. The largest capability gaps for this supplier were for 'effective environmental management system' cluster followed by resource efficiency-related clusters (including water, energy and material).

The capability gaps shown in Figures 3 to 7 for suppliers A to E, in 18 applied outcomes assessed, are all summarized in Figure 8. According to this figure, common gaps in capabilities relating to the following applied outcomes are existed:

- 1.1 Reduce energy use

- 1.2 Maximize alternative energy resources

- 2.1 Reducing water use

- 2.2 Maximize alternative water supply (excluding supplier B)

- 4.1 Implement and apply waste management hierarchy

- 4.2 Handle, store, treat, and dispose waste appropriately

- 5.1 Account for carbon emissions

- 5.2 Reduce carbon emissions

- 6.1 Enhance auditing and environmental monitoring performance

- 6.2 Comply with environmental systems

- 7.1 Implement industrial clustering and resource pooling

- 7.3 Identify, develop, and implement business cases for sustainability improvement

Figure 8. Applied outcome-based capability gaps for suppliers A-E.

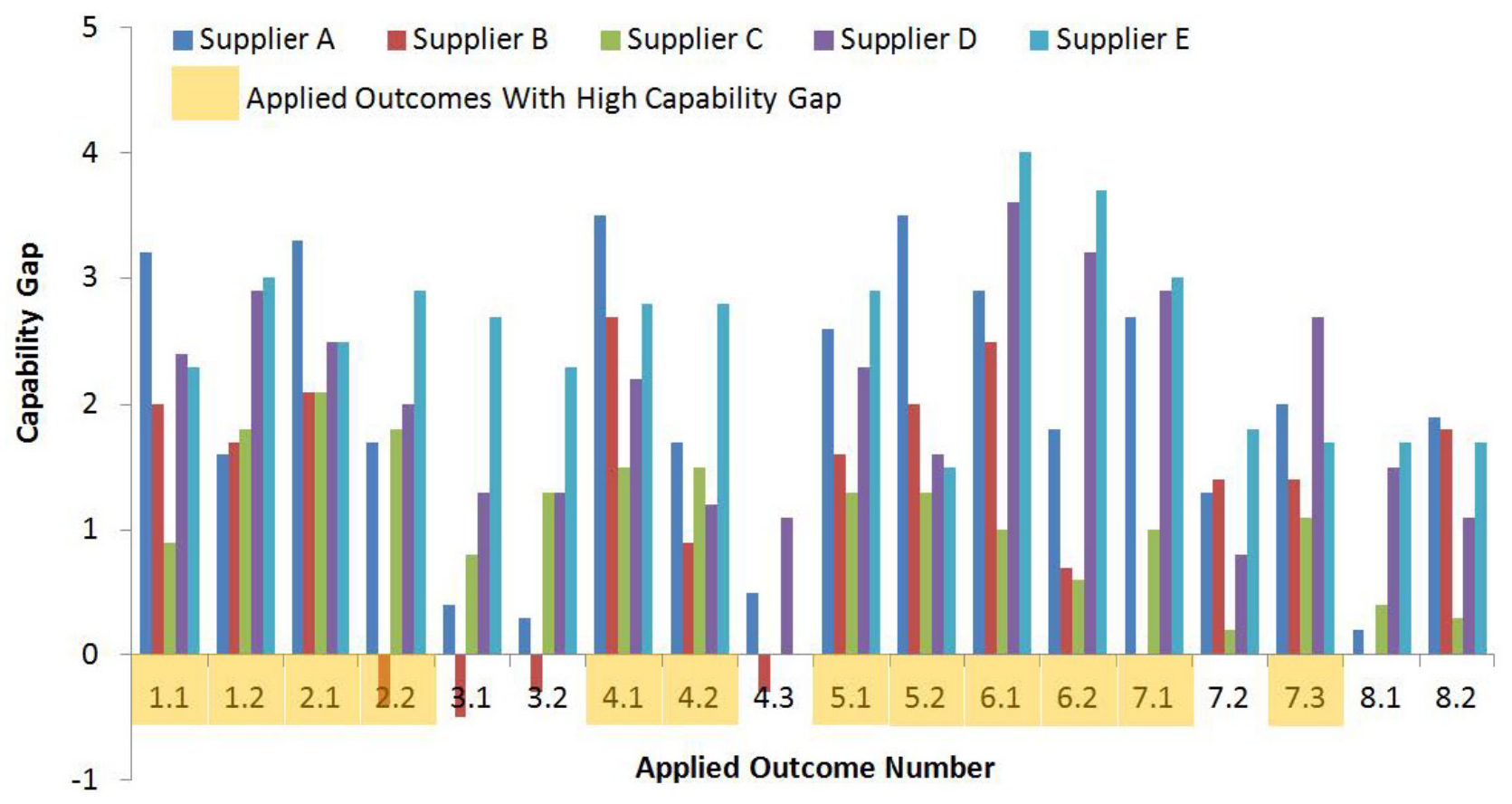


Poor performances in the following capabilities were identified as key contributors to the commonly observed capability gaps as shown in Figure 8:

- Measuring resource consumptions (e.g., energy and water)

- Identifying resource/emission-intensive processes (i.e., hot spot analysis)

- Identifying reasons behind resource/emission-intensive processes

- Performing cost/benefit analysis by effectively taking economic, social, and environmental factors into account to improve their practices from sustainability point of view (i.e., business cases for sustainability improvement)

- Setting up internal environmental targets, strategies, and timelines

- Having a well-established company-based decision making framework/system to achieve the Companies' sustainability targets

- Continuously auditing and monitoring their environmental performance aimed at complying with environmental systems (effective environmental management system)

\section{Training Hierarchy}

The results of gap analysis served to identify the core capability gaps among the suppliers which might limit their ability to meet the industry expectation such as those outlined by the manufacturer through an efficient and cost-effective approach. These knowledge gaps can be broadly classified as insufficient capabilities to:

- identify critical processes to focus on or to identify WHICH processes are resource/ emission-intensive;

- identify the main reasons behind a critical process or to clarify WHY a process is resource/ emission-intensive;

- evaluate the actual costs/benefits of options or WHAT are the actual costs/benefits of the environmental improvement options; and

- compare the various options against the decision criteria or HOW to select the most sustainable option based on the economic, environmental, and social criteria (triple bottom line analysis).

The research team has developed an integrated training framework to address each of these identified knowledge gaps specifically. The proposed training framework shown in Figure 9 is a hierarchy training program consisting of three core training modules that each training modules target a specific managerial level, ranging from the process supervisory for the first module to the senior management for the third one. The training program is expected to empower the suppliers' knowledge relating to fundamentals of sustainable manufacturing, improve the suppliers' skills to measure and collect information required to make better decisions and help suppliers realize the business values of resource efficiency and emissions reduction. These proposed training modules are as follows:

- Measuring and reporting: This module aims to empower the suppliers' knowledge and skills to measure, record, and report the resource consumption and emissions for the processes within their factories. The key training outcome of this module would be the suppliers' capability to identify the most resource-intensive and emissions-intensive processes or conducting hotspot analysis. 
- Analyzing and benchmarking: This module aims to empower the suppliers' knowledge and skills to analyze and benchmark the information collected in Module 1. The key training outcome of this module would be capabilities to identify:

$\checkmark$ the reasons that a specific process is resource/emission intensive or conducting root-cause analysis, and

$\checkmark$ the full costs/benefits of the resource efficiency or emissions reduction options or conducting full-costs accounting

- Knowledge-based decision-making: This module aims to empower the suppliers' knowledge and skills to make sustainable decisions in relation to the resource efficiency and emissions reduction projects. The key training outcome of this module would be the suppliers' capability to conduct multi-criteria decision-making.

Figure 9. Proposed training framework hierarchy.

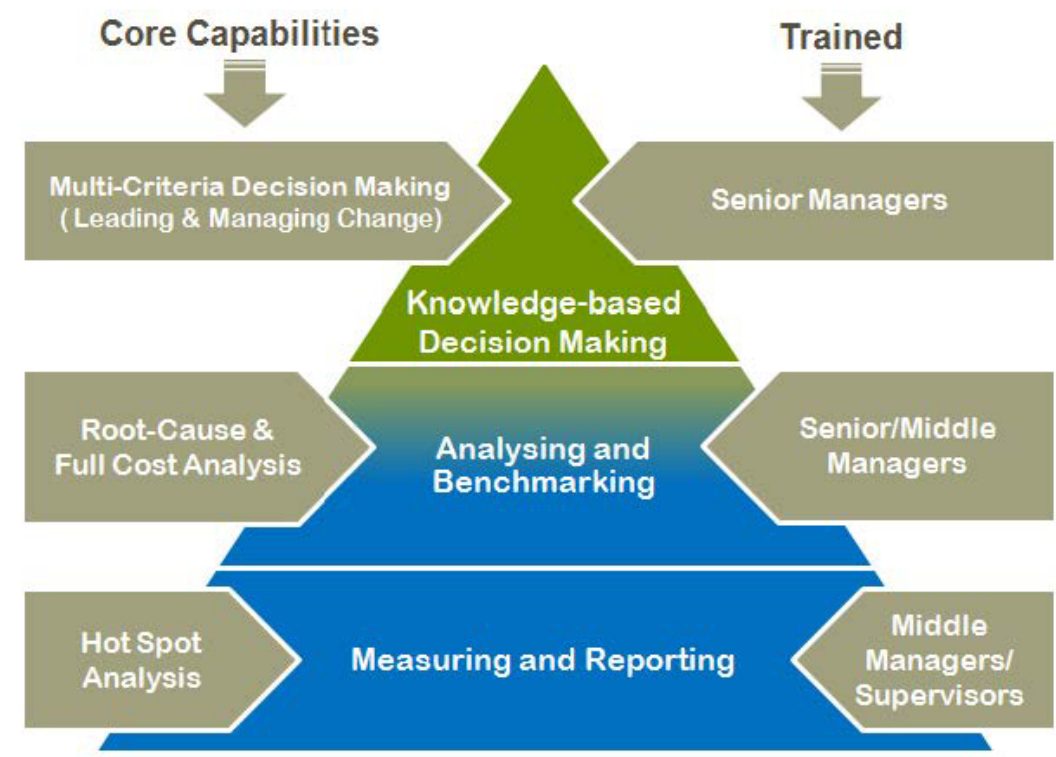

\section{Conclusion}

In this study the authors have reviewed relevant initiatives and practices relating to sustainable manufacturing of sports apparel and sports footwear in order to complete a comprehensive situation analysis of the manufacturing operations of a global sporting goods manufacturer in Southeast Asia. The primary purpose of this investigation was to assess the attainment of core competencies in sustainable manufacturing of sports apparel and footwear across the entire supply chain in the designated region, and to identify and highlight areas for improvement through design and implementation of an appropriate training program. This has involved focus group interviews, surveys and workshops with relevant stakeholders followed by benchmarking of the data gathered against an established competencies metrics. We have developed, for this purpose, a novel Capability Assessment Tool (CAT) for sustainable manufacturing taking into consideration the required standards and practices that can be implemented and enforced along the entire supply chain associated with the manufacturing operations of this global manufacturer's suppliers in Asia. These were streamlined and simplified to ensure more effective performance management using customized training approaches 
and tool-sets. The developed tools have universal appeal as they can be implemented in different contexts and manufacturing settings. The ongoing improvement of sustainable manufacturing capabilities within the supply chain of this manufacturer in the designated region is an important outcome of this project, whereby the capability development program resulting from this research will be implemented (trailed) in the subsequent period involving select number of tier 1 and tier 2 companies in Asia.

Ultimately, this research has enabled us to investigate the possible benefits of forming public-private partnerships with national governments, or international agencies, to build a roadmap for the development and operation of a stand-alone collaborative sustainable manufacturing initiative and/or for the embedding of a standard training program within designated institutions in the region.

\section{Acknowledgments}

The authors wish to acknowledge the invaluable support of the Adidas Group without which this research would not be possible.

\section{Conflict of Interest}

The authors declare no conflict of interest.

\section{References}

1. De Bakker, F.; Nijhof, A. Responsible chain management: A capability assessment framework. Bus. Strategy Environ. 2002, 11, 63-75.

2. Kinderyte, L. Analysis and comparison of methodologies for corporate sustainability assessment. Environ. Res. Eng. Manag. 2008, 4, 66-75.

3. S-CORE Sustainability-Competency, opportunity, reporting \& evaluation. Available online: http://www.sustainability-core.com/ (accessed on 21 March 2011).

4. Seuring, S.; Müller, M. From a literature review to a conceptual framework for sustainable supply chain management. J. Clean. Prod. 2008, 16, 1699-1710.

5. Adidas. Environmental Statement 2010; Global Technology Center Scheinfeld: Scheinfeld, Germany, 2010.

6. Adidas. Sustainability Report 2010, in the Real World Performance Counts; Adidas Group: Herzogenaurach, Germany, 2010.

7. Adidas. Adidas strategy 2015 roadmap and targets. Available online: http://www.adidas-group.com/ en/SER2010/environment/strategy-2015/roadmap-and-targets/Default.aspx (accessed on 20 March 2011).

8. Adidas. The Adidas group environmental strategy 2015. Available online: http://www.adidas-group. com/en/sustainability/assets/environmental_statements/adidasGroup_EnvironmentalStrategy.pdf (accessed on 20 March 2011).

9. Adidas Sustainability. Available online: http://www.adidas-group.com/en/sustainability/welcome. aspx (accessed on 20 March 2011). 
10. Adidas. Health and Safety Guidelines; Adidas Group, Social and Environmental Affairs: Herzogenaurach, Germany, 2010.

11. Adidas. Guide to Best Environmental Practice; Adidas Group, Intechnica GmbH Environmental and management consultants: Nürnberg, Germany, 2005.

12. Adidas. Environmental Guidelines; Adidas Group, Social \& Environmental Affairs: Herzogenaurach, Germany, 2010.

13. Adidas Environmental policy of the Adidas group. Available online: http://www.adidas-group. com/en/sustainability/assets/environmental_statements/adidas_Group_Environmental_Policy.pdf (accessed on 18 March 2010).

14. Adidas Sea key performance indicators (kpis). Available online: http://www.adidas-group.com/ en/ser2010/suppliers/monitoring-compliance/rating-suppliers/Default.aspx (accessed on 22 March 2011).

15. Adidas. Excel Spreadsheet: Environmental Audit Checklist; Social \& Environmental Affairs: Herzogenaurach, Germany, 2010.

16. Adidas. Excel Spreadsheet: Adidas Group Remediation Guidelines for Common Environmental Issues; Social \& Environmental Affairs: Herzogenaurach, Germany, 2010.

17. Adidas. Environmental Metrics Reporting Tool Briefing Note; adidas AG: Herzogenaurach, Germany, 2010.

18. Adidas. Occupational Health and Safety (OHS) Officer Guidance Note; Social \& Environmental Affairs: Herzogenaurach, Germany, 2009.

19. Wirman, C. Adidas Group Indonesia-Energy Efficiency Project; THS Consulting: Gelsenkirchen, Germany, 2009.

20. THS. Energy Efficiency Project Case Study Footwear and Apparel, Adidas Group-Indonesia; THS Consulting: Gelsenkirchen, Germany, 2009.

21. ANTA. National financial services training package-fnb99. Available online: http://training.qld.gov.au/resources/training-organisations/pdf/fnb99-financial-services-v6-0-jan2004.pdf (accessed on 10 March 2011).

22. Department of Education, Employment and Workplace Relations (DEWR). Nwp07 Water Training Package; Australian Government, Department of Education, Employment, and Workplace Relations, Government Skills Australia: Canberra, Australia, 2010.

23. Department of Education, Employment and Workplace Relations (DEWR). Ict10 Integrated Telecommunications; Australian Government, Department of Education, Employment, and Workplace Relations, Innovation and Business Industry Skills Council: Canberra, Australia, 2007.

24. Department of Education, Employment and Workplace Relations (DEWR). Pma08 Chemical, Hydrocarbons and Refining; Australian Government, Department of Education, Employment, and Workplace Relations, Manufacturing Skills Australia: Canberra, Australia, 2011.

25. Department of Education, Employment and Workplace Relations (DEWR). Prm04 Asset Maintenance Training Package; Australian Government, Department of Education, Employment, and Workplace Relations, Construction and Property Services Industry Skills Council: Canberra, Australia, 2009. 
26. Department of Education, Employment and Workplace Relations (DEWR). Psp04 Public Sector Training Package; Australian Government, Department of Education, Employment, and Workplace Relations, Government Skills Australia: Canberra, Australia, 2010.

27. Department of Education, Employment and Workplace Relations (DEWR). Tli07 Transport and Logistics Training Package; Australian Government, Department of Education, Employment, and Workplace Relations, Transport and Logistics Industry Skills Council: Canberra, Australia, 2007.

28. DEST. Mcm04 Competitive Manufacturing Training Package; Australian Government, Department of Education, Employment, and Workplace Relations, Manufacturing Skills Australia: Canberra, Australia, 2006.

29. Global Social Compliance Programme (GSCP). Environmental Implementation Guidelines; Global Social Compliance Program, facilitated by the The Consumer Goods Forum: Issy-les-Moulineaux, France, 2010.

30. International Organization for Standardization (ISO). Environmental Management SystemsRequirements with Guidance for Use; ISO 14001; ISO: Geneva, Switzerland, 2004.

31. International Organization for Standardization (ISO). Guidelines for Quality and/or Environmental Management Systems Auditing; ISO 19011; ISO: Geneva, Switzerland, 2002.

32. National Technical Information Service (NTIS). Bcpps5004a: Conduct a Water Audit and Identify Water-Saving Initiatives; National Training Information Service, Unit of Competency: Alexandria, VA, USA, 2011.

33. National Technical Information Service (NTIS). Bsbpur501a: Develop, Implement and Review Purchasing Strategies; National Training Information Service, Unit of Competency: Alexandria, VA, USA, 2011.

34. National Technical Information Service (NTIS). Bsbmgt608b: Manage Innovation and Continuous Improvement; National Training Information Service, Unit of Competency: Alexandria, VA, USA, 2011.

35. National Technical Information Service (NTIS). Cpccbc4019a: Apply Sustainable Building Design Principles to Water Management Systems; National Training Information Service, Unit of Competency: Alexandria, VA, USA, 2011.

36. National Technical Information Service (NTIS). Icpsu261c: Follow Ohs Practices and Identify Environmental Hazards; National Training Information Service, Unit of Competency: Alexandria, VA, USA, 2011.

37. National Technical Information Service (NTIS). Icpsu323b: Dispose of Waste; National Training Information Service, Unit of Competency: Alexandria, VA, USA, 2011.

38. NTIS. Ictsus7235a: Use Ict to Improve Sustainability Outcomes; National Training Information Service, Unit of Competency: Alexandria, VA, USA, 2011.

39. National Technical Information Service (NTIS). Rtc1701a: Follow Basic Chemical Safety Rules; National Training Information Service, Unit of Competency: Alexandria, VA, USA, 2011.

40. National Technical Information Service (NTIS) Srxres004b: Minimise Waste and Pollution and Their Environmental Impact; National Training Information Service, Unit of Competency: Alexandria, VA, USA, 2011. 
41. National Technical Information Service (NTIS). Srxres005b: Achieve an Efficient Use of Resources; National Training Information Service, Unit of Competency: Alexandria, VA, USA, 2011.

42. National Technical Information Service (NTIS). Tdtu601a: Conduct Environmental Audits; National Training Information Service, Unit of Competency: Alexandria, VA, USA, 2011.

43. National Technical Information Service (NTIS). Thcghs04b: Handle Hazardous Materials Safely; National Training Information Service, Unit of Competency: Alexandria, VA, USA, 2011.

44. Authors. Green and Energy Efficiency Training Units; State Training Services, NSW Department of Education and Communities: Sydney, Australia, 2011.

45. Adidas. Strategy 2015, impacts along the value chain. Available online: http://www.adidas-group. com/en/SER2010/environment/strategy-2015/impacts-along-the-value-chain/Default.aspx (accessed on 29 March 2011).

46. Australian Quality Training Framework (AQTF). Australian qualification training framework publications. Available online: http://www.training.com.au/pages/ menuitem5cbe14d51b49dd34b225261017a62dbc.aspx (accessed on 13 March 2011).

(C) 2012 by the authors; licensee MDPI, Basel, Switzerland. This article is an open access article distributed under the terms and conditions of the Creative Commons Attribution license (http://creativecommons.org/licenses/by/3.0/). 